\title{
A POLÍTICA DE ENSINO MEDIO INTEGRADO COMO GARANTIA DO DIREITO A EDUCAÇÃO DA JUVENTUDE
}

\author{
INTEGRATED HIGH SCHOOL POLICY AS A GUARANTEE OF YOUTH \\ RIGHT TO EDUCATION \\ LA POLÍTICA INTEGRADA DE LA ENSEÑANZA MEDIA COMO GARANTÍA
DEL DERECHO DE LOS JÓVENES A LA EDUCACIÓN
}

Rachel Costa de Azevedo Mello*

(iD http://orcid.org/oooo-ooo2-5726-1557

Jaqueline Moll ${ }^{* *}$

http://orcid.org/oooo-ooo1-5465-178X

\begin{abstract}
REVISTA PEDAGÓGICA
Revista do Programa de Pós-graduação em Educação da Unochapecó | ISSN 1984-1566 Universidade Comunitária da Região de Chapecó | Chapecó-SC, Brasil Como referenciar este artigo: MELLO, R. C. A.; MOLL, J. A política de Ensino Médio Integrado como garantia do direito à educação da juventude. Revista Pedagógica, Chapecó, v. 21, p. 266-291, 2019. DOI: http://dx.doi.org/10.22196/rp.v22io.5108
\end{abstract}

RESUMO: O presente artigoé uma pesquisa bibliográfica que tem por objetivo analisar a política de Ensino Médio Integrado à Educação Profissional como um caminho para a garantia do direito à educação da juventude e enfrentamento das desigualdades educacionais no contexto brasileiro. Realizamos uma discussão conceitual sobre o tema. Concluímos que o Ensino Médio Integrado busca enfrentar o dualismo que marcou praticamente todas as propostas e políticas públicas destinadas a esta etapa da escolarização, ao propor uma formação integrada, abrangendo um conjunto de conhecimentos que relacionam ciência, tecnologia, cultura e o mundo do trabalho, essencial para a compreensão e inserção no mundo contemporâneo.

Palavras-chave: Ensino médio integrado. Política em educação. Direito à educação.

ABSTRACT: This article is a bibliographic research that aims to analyze the policy of High School integrated to professional education as a way to guarantee the right to education of the young ones and also to confront educational inequalities in the Brazilian context. We held a conceptual discussion on the topic. It's apparent that professional training during High School seeks to face the dualism that practically defined all proposals and public policies aimed at this stage of schooling, by proposing an integrated education and embracing a set of skills that relates to science, technology, culture and the business world, essential for understanding and insertion into the contemporary world.

Keywords: Integrated high school. Education policy. Right to education.

RESUMEN: Este artículo es una investigación bibliográfica cuyo objetivo es analizar la política de la enseñanza media integralizada a la educación profesional como una forma de garantizar el derecho a la educación de los jóvenes y de enfrentar las desigualdades educativas en el contexto brasileño. Para ello, realizamos una discusión conceptual sobre el tema. Concluimos que Integrated High School busca enfrentar el dualismo que marcó prácticamente todas las propuestas y políticas públicas dirigidas a esta etapa de la escuela, al proponer una educación integrada, que abarque un conjunto de conocimientos que relacionen la ciencia, la tecnología, la cultura y el mundo del trabajo, esencial a la comprensión y la inserción en el mundo contemporáneo.

Palabras clave: escuela secundaria integrada; política educativa; derecho a la educación. 


\section{Introdução}

O presente artigo tem como objetivo realizar uma reflexão sobre a política de Ensino Médio Integrado à Educação Profissional como um caminho para a garantia do direito à educação da juventude e para o enfrentamento das desigualdades educacionais no contexto brasileiro. A garantia dos direitos educativos da juventude no Brasil está relacionada à execução de políticas em educação que possibilitem o avanço da escolaridade, condições de acesso, de permanência e de qualidade na escola, articuladas a políticas públicas que proporcionem condições dignas de vida à população. Consideramos políticas em educação para juventude como políticas públicas inclusivas, diante da histórica e abissal desigualdade social do Brasil, resultado de um projeto de sociedade excludente que está na raiz da nossa formação como nação.

As políticas inclusivas, assim, podem ser entendidas como estratégias voltadas para a universalização de direitos civis, políticos e sociais. Elas buscam, pela presença interventora do Estado, aproximar os valores formais proclamados no ordenamento jurídico dos valores reais existentes em situações de desigualdade [...] Elas se voltam para indivíduo e para todos, sustentadas pelo Estado, pelo princípio da igualdade de oportunidades e pela igualdade de todos ante a lei. (CURY, 2005, p. 14-15).

Cury chamou de políticas públicas "includentes", aquelas formuladas a partir dos conceitos de igualdade e de universalização, que têm em vista a redução das desigualdades em uma sociedade de classes. "E elas têm como meta combater todas e quaisquer formas de discriminação que impeçam o acesso a maior igualdade de oportunidades e de condições" (CURY, 2005, p. 15). Considerando essa perspectiva ${ }^{1}$, as políticas em educação são essenciais para a conquista da equidade e da justiça social e como forma de corrigir as desigualdades educacionais no Brasil que, naturalizadas, vêm acarretando uma série de obstáculos à vida de crianças e jovens brasileiros (CURY, 2005, p. 15).

O compromisso com as políticas públicas em educação de um governo demonstra a importância dada a garantia dos direitos humanos fundamentais, o que inclui a escolarização da juventude, além de ser um fator determinante para o desenvolvimento social, e, em particular, o Ensino Médio, constitui uma etapa decisiva da trajetória dos jovens, estes que não podem estar à "deriva" nem submetidos à reprodução social das desigualdades educacionais. A garantia do direito à educação deve, portanto, obedecer à Constituição Brasileira que, no seu Capítulo III, prescreve: "Art. 206. O ensino será ministrado com base nos
* Universidade Federal Rural de Pernambuco (UFRPE). Atualmente cursa doutorado pelo Programa de Pós-Graduação em Educação em Ciências: Química da Vida e Saúde na Universidade Federal do Rio Grande do Sul (UFRGS) - Departamento de Bioquímica.

** Universidade Federal do Rio Grande do Sul (UFRGS). Doutora em Educação pela UFRGS. Professora Titular da UFRGS - Faculdade de Educação. Professora colaboradora do Programa de Pós-graduação em Educação em Ciências: Química da Vida e Saúde - UFRGS. Profesora colaboradora Professora do Programa de Pós-Graduação em Educação da Universidade Regional Integrada do Alto Uruguai e das Missões (URI).

1 Em outro enfoque conceitual, as políticas inclusivas podem também ser focadas em grupos marcados por uma diferença específica e em situação de vulnerabilidade, "dentro daquela qualidade histórica a que Bobbio (1992) chama especificação de direitos. Trata-se do direito à diferença, no qual se mesclam as questões de gênero com as de etnia, idade, origem, religião e deficiência, entre outras" (CURY, 2005, p. 16). 
seguintes princípios: I - igualdade de condições para o acesso e permanência na escola" (BRASIL, 1988).

Para Nosella (2015, p. 123): "[...] o ensino médio é a fase escolar estratégica do sistema escolar e do processo de democratização e modernização de uma nação". A esse respeito, Frigotto e Ciavatta (2011, p. 632) questionam: “[...] não se constituiria este um nível estratégico da formação básica para o trabalho e a atuação política, social e cultural dos jovens?” E acrescentam: “[...] e não seria também fundamental para o desenvolvimento científico e tecnológico do país, de modo a ampliar os graus de autonomia e soberania nacional?" (FRIGOTTO; CIAVATTA, 2011, p. 632). A resposta às questões seria afirmativa com a ressalva de que o Ensino Médio, enquanto etapa destinada à educação da juventude, não pode estar submetido ou adaptado às demandas específicas e inconstantes do mercado. No contexto capitalista periférico, como é o caso do Brasil, os interesses e as prioridades estiveram historicamente atrelados a uma formação precária para a juventude pobre, que manteve a lógica de divisão de classes, em oposição à distribuição de renda, à igualdade de direitos, ao desenvolvimento sustentável ou à preservação da vida e do planeta.

Pensando no ensino médio, não se trata, pois, de mera adaptação às mudanças no mundo da produção e do trabalho, tais como adaptar-se à flexibilização produtiva, à "sociedade da incerteza”, às relações de trabalho desregulamentadas, ao empreendedorismo, aos programas breves de aprendizagem, aos programas paliativos da tensão social. Há condições de vida que permeiam as opções das pessoas. E estas passam pela forma histórica como produzem a própria vida. (CIAVATTA, 2014, p. 188).

Diante das incertezas e da exploração do mundo do trabalho, a educação da juventude deve estar voltada a uma formação crítica, ampla e diversificada, como também à reflexão sobre o sistema social, buscando, desse modo, alternativas de desenvolvimento econômico com inclusão social, pautadas na ampliação da esfera pública e que expresse a máxima: "nenhum a menos", sendo esta entendida na perspectiva de um mundo em que todos caibam. Tais processos implicam que a trajetória do Ensino Médio seja marcada por situações reais que permitam aos jovens experienciar vivências formativas significativas no campo da cultura, das artes, das tecnologias, das ciências e do trabalho, conforme apontam as Diretrizes Curriculares Nacionais para o Ensino Médio². Tal perspectiva somente é possível no contexto de um projeto de sociedade que inclua um projeto de escolarização de qualidade para a juventude pobre, que não pode ser marginalizada, nem refém da violência, nem se conformar à redenção de "escolas pobres para os pobres".
2 Diretrizes Curriculares Nacionais para o Ensino Médio. Resolução no ${ }^{3}$, de 21 de novembro de 2018 que "Atualiza as Diretrizes Curriculares Nacionais para o Ensino Médio". 


\section{Ensino Médio como direito à educação da juventude}

Diante do imenso desafio da escolarização da juventude, apontamos questões que indagam o caráter historicamente dual do Ensino Médio: qual seria a finalidade do Ensino Médio? Seria dar continuidade aos estudos para ingresso no ensino superior? Ou preparar para o mundo do trabalho? É de fundamental importância refletir sobre o sistema dual ${ }^{3}$ que marcou, de modo indelével, praticamente todas as propostas e políticas públicas destinadas a essa etapa da escolarização. Do mesmo modo que entendemos ser reducionista um Ensino Médio destinado a formar para atender a necessidades e interesses do mercado, não podemos ignorar as exigências da produção econômica, inclusive como modo de garantir a manutenção da vida material.

Entretanto, diante do contexto de desigualdade e precarização do mundo do trabalho, não podemos descartar uma formação para o trabalho, mas precisamos ir além: promover a compreensão crítica da dinâmica sócio-produtiva das sociedades contemporâneas, o que significa uma formação para o entendimento amplo sobre o trabalho produtivo, que supere a dicotomia entre trabalho manual e intelectual.

Nesse sentido, apesar da proposição de políticas públicas em educação inclusivas nas duas últimas décadas, resultado da ação dos quatro últimos governos ${ }^{4}$, anteriores ao processo de impeachment de Dilma Rousseff, ainda se verificam desafios e entraves nesta etapa da escolarização. Dados estatísticos sobre a situação do Ensino Médio no Brasil atestam um longo percurso para a conquista da qualidade da educação, em relação ao desempenho dos alunos, ao acesso à escola, à permanência, à aprendizagem e ao contexto socioeconômico das escolas. Os dados são indispensáveis para verificar a qualidade do ensino, monitorar os sistemas educacionais e, principalmente, para a criação de políticas públicas em educação e serviços escolares.

De acordo com o Censo Escolar 2017, havia 184,1 mil escolas de educação básica no Brasil, nas quais 48,6 milhões de estudantes estavam matriculados. Verificamos que em 2017 o Ensino Fundamental era ofertado por 71,5\% das escolas, o que equivale a 131,6 mil escolas, onde foram registradas 27.348.080 matrículas. Já o Ensino Médio era ofertado, no mesmo ano, em somente $15 \%$ do total de escolas brasileiras, o que equivale a 28,5 mil escolas, onde estavam matriculados 7.930.384 milhões de estudantes.

Com esses dados, observamos uma diminuição significativa entre o percentual de escolas e número de estudantes do Ensino Médio comparado ao do Ensino Fundamental, o que demonstra a dificuldade no acesso e continuidade dos estudos, tendo nessa passagem/transição "um gargalo" ou "degrau" muito alto para determinados grupos sociais. Apesar de muitos ficarem pelo caminho, ao não ingressarem no Ensino Médio, ainda podemos falar em garantia de
3 Refere-se à separação entre a formação geral e a formação profissional no Ensino Médio/secundário.

\begin{abstract}
4 Sobre avanços das políticas públicas, destacamos as políticas educacionais dos governos de Luiz Inácio Lula da Silva e Dilma Rousseff (2003-2016): a Emenda Constitucional $n^{0}$ 59/ 2009 (prevê a obrigatoriedade do ensino de quatro a dezessete anos e amplia a abrangência dos programas suplementares para todas as etapas da educação básica) e a Lei ${ }^{0} 12.796 / 2013$ (dispõe sobre a formação dos profissionais da educação), a Lei $n^{0}$ 12.061/2009 (assegura o acesso ao ensino médio público); a Lei $\mathrm{n}^{0}$ 11.494/2007 (regulamenta o Fundeb, corrigindo as distorções de destinação de recursos financeiros, provocadas pelo Fundef); a Lei $\mathrm{n}^{0}$ 11.274/2006 (dispõe sobre a duração de nove anos para o ensino fundamental, com matrícula obrigatória a partir dos seis anos de idade); a Lei $n^{0} 11.114 / 2005$ (torna obrigatório o início do ensino fundamental aos seis anos de idade); o Decreto ${ }^{0}$ 6.861/2009 (dispõe sobre a educação escolar indígena e define sua organização em territórios etnoeducacionais) e o Decreto $n^{0}$ 6.949/2009 (promulga a Convenção Internacional sobre os Direitos das Pessoas com Deficiência) entre outras.
\end{abstract}


direitos educativos, uma vez que a maioria dos estudantes brasileiros estão matriculados em escolas públicas estaduais, diga-se $68,2 \%$, enquanto $29,0 \%$, estão em escolas privadas.

Considerando os dados, o Ensino Médio, enquanto direito educativo constitucional e etapa final da educação básica ${ }^{5}$ de responsabilidade do poder público, não pode ser tratado com descaso ou estar atrelado à lógica mercadológica e, sim, ser compreendido como direito educativo da juventude, como parte do ciclo formativo, já que é um dever do Estado garantir a todos os cidadãos e cidadãs esse direito. Assim, este se insere nos direitos humanos e sociais; e, a partir de políticas públicas em educação, deve ser viabilizado pela escola pública, laica, gratuita e de qualidade. Apesar disso, segundo Moll (2017, p. 63):

A consciência do direito de todos ao ensino médio é, ainda, na sociedade brasileira, um evento recente e não incorporado, do mesmo modo como lento e tardio foi o processo de incorporação do direito ao ensino fundamental, tanto na sua etapa primária, quanto ginasial, ao longo de todo século XX. Em que pese a quase universalização do ensino fundamental nos últimos 20 anos, as elevadas taxas de retenção e evasão dos estudantes demonstram, entre outros fatores, o não apreço à presença das classes populares em processos estendidos de escolarização.

Com muitos anos de atraso, o direito à educação da juventude é uma demanda social de extrema urgência, uma vez que não se pode colocar em risco a independência e o futuro do país quando não se garante o acesso à educação de qualidade, previsto em lei, a jovens brasileiros. Em seu artigo "Educação como desafio na ordem jurídica", Carlos Jamil Cury (2000, p. 568) discute as questões do direito à educação: "a educação escolar entra como referência e como um direito de cidadania".

O autor traz uma, ainda, reflexão sobre o conceito de direito: "[...] o termo direito deriva do verbo latino dirigere e significa dirigir, ordenar. Essa expressão foi assumida pela área jurídica, passando a recobrir vários sentidos. Um deles é o de norma, rota que dirige ou ordena uma ação individual ou social" (CURY, 2000, p. 567). Assim, ressalta que o direito é um conjunto de normas ou regras, dentro de uma dada ordem jurídica, pelas quais as pessoas ou grupos têm ou não o poder, e quando transformadas em lei, “[...] o direito implica, ao mesmo tempo, o reconhecimento de uma prerrogativa e de um limite cuja transgressão implica uma pena" (CURY, 2000, p. 567).

O direito se viu enriquecido com outras significações dentre as quais a de um acesso a uma proteção contra uma ameaça ou a de um
5 A Emenda Constitucional EC $\mathrm{n}^{\mathrm{o}}$ 59/2009 estabeleceu sua obrigatoriedade para a faixa etária dos 15 aos 17 anos. 
usufruto de uma prerrogativa indispensável para um indivíduo ou uma coletividade. Mas a história mostra, também, a existência de múltiplas ordens jurídicas, entre as quais aquela que é assumida pelos Estados e Nações como forma de ordenar as relações sociais e as prerrogativas das pessoas. Trata-se da ordem jurídica estatal. (CURY, 2000, p. 567).

Portanto, o Estado necessita de políticas públicas enquanto conjunto de prescrições/induções e como forma de regulação das relações sociais e de legitimar determinadas conquistas que dizem respeito aos interesses das coletividades.

O direito deve ser declarado e entre os modos de se declarar um direito o mais disseminado é pela via escrita [...]. Declarar direitos é um recurso político-pedagógico que expressa um modo de conceber as relações sociais dentro de um país. É também um instrumento voltado à memória individual ou coletiva a fim de lembrar ou relembrar quem esqueceu de tomar ciência dos direitos. (CURY, 2000, p. 567).

Nesse sentido, as políticas públicas ao representar os direitos, os anseios e as necessidades populares, viabilizam a democracia como Estado de direito de uma nação. Para Cury (2000, p. 568-569):

O reconhecimento da importância do direito e da legislação que o expressa tem o seu ponto alto quando se fundamenta na soberania popular. [...] É essa capacidade da pessoa se inserir com condições equitativas mínimas na ordem jurídica de um país e de poder participar igualmente nos destinos de sua comunidade que a define no espaço da cidadania.

No entanto, a educação enquanto direito é uma conquista recente, pois foi somente declarada em lei no fim do século XIX e início do século XX, o que nos faz perceber o quanto foi negado à grande parte da população mundial. Sobre o direito à educação, Cury (2000, p. 569) afirma que "o Brasil ainda é um país endividado com sua população". De fato, a educação escolar somente tornou-se obrigatória na Constituição Republicana de 1934, inspirada nos ideais dos Pioneiros da Educação Nova, na qual o direito à educação foi reconhecido como dever do Estado: "Artigo 149 - a educação é um direito de todos e deve ser ministrada pela família e pelos poderes públicos, cumprindo a estes proporcioná-la a brasileiros e estrangeiros domiciliados no país [...]"; e ainda no "Artigo 156 - A União e os Municípios aplicarão nunca menos de dez por cento, e os Estados e o 
Distrito Federal nunca menos de vinte por cento, da renda resultante dos impostos na manutenção e no desenvolvimento dos sistemas educativos" (BRASIL, 1934). Nesse sentido, sobre o direito à educação:

Ele é um produto dos processos sociais levados adiante pelos segmentos de trabalhadores que viram nele um meio de participação na vida econômica, social e política. Seja por razões políticas, seja por razões ligadas ao indivíduo, a educação era vista como um canal de acesso aos bens sociais e à luta política e como tal um caminho também de emancipação do indivíduo frente a ignorância. (CURY, 2000, p. 569).

No entanto, somente três anos depois, o direito à educação assegurado pelo Estado e o financiamento público foram excluídos, do texto da lei, na Constituição de 1937, que determinou no seu art. 128: "A arte, a ciência e o ensino são livres à iniciativa individual e a de associações ou pessoas coletivas públicas e particulares" (BRASIL, 1934). E ainda no art. 129: "A infância e à juventude, a que faltarem os recursos necessários à educação em instituições particulares, é dever da Nação, dos Estados e dos Municípios assegurar, pela fundação de instituições públicas de ensino em todos os seus graus, [...]" (BRASIL, 1934). Basicamente não sobrou nada - com a Constituição de 1937 - em termos de direito à educação assegurado pelo Estado.

Essa dívida social histórica com a educação do povo nos remete a possíveis explicações. Para Cury (2000, p. 570), o Brasil tem um itinerário típico de um país nascido colônia "[...] que não pôde usufruir da soberania nacional de 1500 até 1822 e somente no início do século XX é que se pôde falar expressamente da busca de um direito social no Brasil", o que limitou nossa independência e desenvolvimento como nação soberana e democrática:

Após a independência, os determinantes internos e externos limitaram seu desenvolvimento como nação soberana; além disso, o regime escravocrata associado ao estatuto da "civilização dos índios" incide profundamente sobre a noção e a prática de direitos civis e políticos. (CURY, 2000, p. 570).

Tais reflexões devem constituir referências para superarmos os processos de sonegação de uma escolarização sólida e diversificada, com qualidade social a todas as crianças e jovens. O direito à educação, ao ser negado, sempre conduziu - e conduzirá - à exploração econômica e à dominação cultural da maioria do povo brasileiro: o povo, que não conhece os seus direitos, está fadado a resignar-se diante de governos que tratam os direitos humanos e sociais como privilégios, sobretudo em estruturas sociais 
muito desiguais. A propósito, Paulo Freire (1987, p. 83) adverte que:

Através da manipulação, as elites dominadoras vão tentando conformar as massas populares a seus objetivos. E, quanto mais imaturas, politicamente, estejam elas (rurais ou urbanas) tanto mais facilmente se deixam manipular pelas elites dominadoras que não podem querer que se esgote seu poder.

A juventude brasileira precisa constituir um horizonte de justiça social que inclua educação, emprego, saúde, alimentação, moradia, cultura e lazer como direitos fundamentais humanos e sociais, independente de classe ou condição social.

O que assegura, portanto, a "justiça" e a legitimidade do privilégio moderno é o fato de que ele seja percebido como conquista e esforço individual. Nesse sentido, podemos falar que a ideologia principal do mundo moderno é a "meritocracia", ou seja, a ilusão, ainda que seja uma ilusão bem fundamentada na propaganda e na indústria cultural, de que os privilégios modernos são "justos". Sua justiça reside no fato de que "é do interesse de todos" que existam "recompensas" para indivíduos de alto desempenho em funções importantes para a reprodução da sociedade. O "privilégio" individual é legitimado na sociedade moderna e democrática, fundamentada na pressuposição de igualdade e liberdade dos indivíduos, apenas e enquanto exista essa pressuposição. (SOUZA, 2009, p. 43).

Acerca deste tema, justificativas hegemônicas como o falso discurso da meritocracia, enquanto compreensão hierarquizada do mundo, deslocam o problema das desigualdades e da negação de direitos para um terreno individual de falta de esforço pessoal ou mérito próprio, gerando, assim, conformismo e estagnação para mudança da situação de exclusão. Em outras palavras: a desigualdade, de todas as ordens, sempre está relacionada às condições materiais de existência. No caso do Brasil, gerações inteiras "nasceram" desiguais, e não porque o esforço individual não foi suficiente.

No caso brasileiro, a justificação da desigualdade pelo "esquecimento" do pertencimento de classe e, portanto, da gênese social das diferenças individuais que aparecem como atributo (miraculoso) do mérito individual é mil vezes potencializada por uma aliança invisível com o mito da brasilidade. [...], o mito da brasilidade tem a ver tanto com a construção 
de uma ficção de homogeneidade e de unidade entre brasileiros tão desiguais quanto com "horror ao conflito". É verdade que todo mito nacional tem a ver com reforço de uma unidade real ou imaginária como forma de criar um sentimento de solidariedade do tipo "estamos todos no mesmo barco". Mas esse sentimento de pertencimento comunitário não precisa demonizar o conflito. (SOUZA, 2009, p. 47).

Arroyo (2012, p. 36) afirma que há uma tendência de pensar sobre a infância-adolescência "[...] tendo como referência representações sociais tão arraigadas em nossa cultura política segregadora, inferiorizante e preconceituosa". Significa ver o povo como subalternos como "foram e continuam sendo vistos ao longo de nossa formação social, política e cultural”. Para o autor, há uma visão persistente na escola e na gestão do sistema escolar, e daqueles que fazem as políticas: é uma forma de pensar as "infâncias-adolescências populares" que, em grande medida, influencia a concepção das políticas educativas. Segundo Arroyo, significa enxergá-los de forma negativa, preconceituosa, como atrasados mentais, como carentes de valores, dedicação, esforço, de cultura, de racionalidade:

[...] com problemas de aprendizagem, lentos, desacelerados, consequentemente classificados no percurso seletivo escolar como reprovados, repetentes, defasados, incapazes de seguir com êxito o percurso normal de aprendizagem, logo, fracassados escolares e sociais. (ARROYO, 2012, p. 37).

Essa visão negativa sobre os estudantes advindos dos setores populares "foi acompanhada de sua inferiorização moral ao longo da história, desde a 'empreitada colonial civilizatória', considerados como imorais, uma ameaça a condutas morais sadias (ARROYO, 2012, p. 37). E não somente como "inferiores", mas classificando-os como indisciplinados ou violentos, gerando o perigo e o medo da infância-adolescência popular. Apesar dessa visão negativa influenciar a proposição de políticas e programas, Arroyo (2012) propõe superá-la destacando "o protagonismo positivo" da infância e da juventude pobre:

[...] seus esforços por sobrevivência, por cuidado, seus gestos de autoproteção e de proteção a seus irmãos, sua colaboração na escassa renda familiar; [...] sua participação em tantas ações coletivas populares pró-terra, pró-teto e moradia, pró-água, luz, transporte, cultura, humanização dos espaços; [...] seus esforços por articular tempos de trabalho e sobrevivência e tempos de escola, sua ética e 
seus exercícios de liberdade nos limites mais extremos. (ARROYO, 2012, p. 38).

Nesse sentido, Moll (2017) afirma a importância das políticas públicas como "fendas" que podem aproximar a juventude pobre do acesso à educação rumo à diminuição das desigualdades e à mudança social.

Fendas que fomentaram fortes reações daqueles historicamente acostumados com um país, cujos donos sempre garantiram a seus filhos as melhores colocações, seja nas universidades, seja no mercado de trabalho, caracterizando um "modelo meritocrático" em que o esforço pessoal é quase que completamente substituído pelas garantias do berço e do sobrenome. (MOLL, 2017, p. 63).

"Fendas" que, literalmente, significam "rachaduras" ou "qualquer abertura estreita que permita a passagem de luz", o que abre a possibilidade de um horizonte possível de processos educativos comprometidos com o direito à educação de todas e todos.

\section{O Ensino Médio Integrado}

O Ensino Médio Integrado à Educação Profissional constitui, hoje, como política pública em educação, uma das "fendas" abertas na direção da garantia do direito à educação da juventude brasileira. Vem sendo experimentado $^{6}$, enquanto política de educação que propõe uma formação integrada/unificada, abrangendo um conjunto de conhecimentos que relacionam ciência, tecnologia, cultura e o mundo do trabalho, essenciais para compreensão do mundo contemporâneo.

Na última década foram abertas fendas neste desenho social, através de diferentes políticas públicas, entre as quais, a de redistribuição de renda e de acesso popular ao ensino superior, tanto através do sistema de cotas, como através da expansão de vagas públicas ou financiadas pelo poder público. Significativo número de jovens pobres constituíramos primeiros, em gerações e gerações de suas famílias, a concluir o ensino médio e a chegar ao ensino superior. (MOLL, 2017, p. 63).

Para Ciavatta (2014), a expressão "formação integrada" também está relacionada com a defesa da democracia e da escola pública e à luta pela superação do dualismo estrutural da sociedade e da educação brasileiras: respectivamente, a divisão de classes e "a divisão entre formação para o trabalho manual ou para o trabalho intelectual" (CIAVATTA, 2014, p. 197).

\footnotetext{
6 De acordo com as Notas estatísticas do Censo escolar 2017, a matrícula na modalidade de ensino médio integrado que era, em 2016, de 6,4\%, cresceu 4,2\%, passando de 531.824, em 2016 para 554.319, em 2017. Em 2017, na rede pública, a modalidade integrada teve maior número de matrículas: 565.394. A modalidade concomitante ficou com 100.249 matrículas, a subsequente com 390.120 e os cursos de formação continuada tiveram 21.387 matriculados (BRASIL, 2017).
} 
Do ponto de vista do conceito, formação integrada significa mais do que uma forma de articulação entre ensino médio e educação profissional. Ela busca recuperar, no atual contexto histórico e sob uma específica de correlação de forças entre as classes, a concepção de educação politécnica, de educação omnilateral e de escola unitária, que esteve na disputa por uma nova LDB na década de 1980 e que foi perdida na aprovação da Lei $\mathrm{n}^{\circ}$ 9.394/96. (CIAVATTA, 2014, p. 197).

O dualismo na formação da juventude é um processo datado, que vem contribuindo para a divisão social do trabalho e para sociedade de classes:

Desde o final do século XIX, com a criação de escolas profissionais e técnicas ao lado dos tradicionais ginásios e liceus, clássicos e científicos, abriu-se entre os educadores o debate sobre a dualidade escolar. Com efeito, a existência de dois sistemas escolares, de cultura geral "desinteressada" para os futuros dirigentes da sociedade e de preparação técnica e profissional para os quadros do trabalho, levou corações e mentes sinceramente humanistas, entre os quais muitos educadores marxistas, a defenderem um sistema escolar unitário de educação básica, considerando essa dualidade expressão da injustiça social. (NOSELLA, 2015, p. 126).

Segundo Souza, Costa Júnior e Souza (2018, p. 647), pesquisadores brasileiros - dentre eles, Moura e Lima Filho (2017); Ramos (2012); Araújo; Rodrigues; Silva (2014); Ciavatta (2014); Araújo; Frigotto (2015); Moura; Lima Filho; Silva, (2015) - veem "[...] no Ensino Médio Integrado [...] um cenário promissor para a formação de trabalhadores baseada nas concepções teórico conceituais da omnilateralidade e da politecnia, presentes nos escritos de Marx e Engels, e da escola unitária, nos estudos de Gramsci”.

Embora a temática da escola única ou unitária esteja presente em todo o pensamento pedagógico do século XX, o foco deste texto dirige-se à proposta de escola unitária de Antonio Gramsci. Há razões para privilegiar esse autor, uma vez que seu nome está emblematicamente associado à tese da escola unitária, cujos textos estão muito presentes no debate brasileiro. (NOSELLA, 2015, p. 127).

Para Nosella (2015, p. 132), Gramsci cogitou uma nova hegemonia que "[...] prioriza a dilatação da função da intelectualidade das massas trabalhadoras e, por isso, a escola secundária tradicional devia ser modernizada e 
universalizada, não substituída por escolas populares medíocres, subalternas, de iniciação profissional”. Ciavatta (2014) baseia-se em Gramsci para teorizar a respeito da ideia de trabalho como princípio educativo, como um aporte teórico fundamental para o Ensino Médio Integrado e também como uma crítica a educação dual que marcou o Ensino Médio no Brasil, além de ser um princípio formativo que articula a formação técnica e cultural, política e social. Ciavatta (2014) nos informa que:

A formação integrada, a educação politécnica e a educação omnilateral tem exemplos históricos no sistema educacional do início da Revolução Russa de 1917, na Revolução Cubana de 1959 e nas lutas pela democratização do ensino no Brasil, nos anos 1980, [...] quando se introduziu o termo educação politécnica no primeiro projeto da LDB e, nos anos 2000, quando se implementou a discussão e tentativas de implantação da formação integrada. (CIAVATTA, 2014, p. 202).

Na formação integrada, para Ciavatta (2014, p. 198), a educação geral é inseparável da educação profissional "[...] em todos os campos em que se dá a preparação para o trabalho: seja nos processos produtivos, seja nos processos educativos como a formação inicial, como o ensino técnico, tecnológico ou superior".

O termos formação integrada, formação politécnica e, mais recentemente, educação tecnológica buscam responder, também, às necessidades do mundo do trabalho permeado pela presença da ciência e da tecnologia como forças produtivas, geradoras de valores, fontes de riqueza. Mas, também, por força de sua apropriação privada, gênese da exclusão de grande parte da humanidade relegada às atividades precarizadas, ao subemprego, ao desemprego, à perda dos vínculos comunitários e da própria identidade. (CIAVATTA, 2005, p. 3).

Para a autora, significa que se deve enfocar o trabalho como princípio educativo a fim de superar "a dicotomia trabalho manual/trabalho intelectual", visando a incorporar "[...] a dimensão intelectual ao trabalho produtivo e formar trabalhadores capazes de atuar como dirigentes e cidadãos" (GRAMSCI, 1981, p. 144 apud CIAVATTA, 2014, p. 198).

O ensino médio integrado procura estabelecer um vínculo entre o aprendizado profissional e o acadêmico. Trata-se de um curso único, com a integração e a interdepen- 
dência de todos os componentes curriculares quer os mais voltados para a formação geral, quer os relativos à base tecnológica de determinada habilitação profissional -, oferecidos simultaneamente, desde o início até a conclusão do curso. Não é possível concluir o ensino médio sem a conclusão do ensino técnico de nível médio e vice-versa. (KRAWCZYK, 2014, p. 28).

Segundo Frigotto e Ciavatta (2011, p. 624), "o termo "politecnia" foi apropriado no sentido da educação socialista do início do século XX como "[...] domínio dos fundamentos científicos das diferentes técnicas que caracterizam o processo de trabalho produtivo moderno (SAVIANI, 1989, p. 17)"; sendo reafirmado por "Saviani (2003), Kuenzer (1988), Machado (1989), Frigotto (1988) e Rodrigues (1998)". Já o termo "ominilateral” tem origem histórica "na educação socialista, politécnica ou tecnológica (Marx, 1980)" que significa formação humana "na sua integralidade física, mental, cultural, política e científico-tecnológica" (FRIGOTTO; CIAVATTA, 2011, p. 626). Para Ciavatta:

A formação integrada sugere tornar íntegro, inteiro, o ser humano dividido pela divisão social do trabalho entre a ação de executar e a ação de pensar, dirigir ou planejar. Trata-se de superar a redução da preparação para o trabalho ao seu aspecto operacional, simplificado, escoimado dos conhecimentos que estão na sua gênese científico tecnológica e na sua apropriação histórico-social. Como formação humana, o que se busca é garantir ao adolescente, ao jovem e ao adulto trabalhador o direito a uma formação completa para a leitura do mundo e para a atuação como cidadão pertencente a um país, integrado dignamente à sua sociedade política. (CIAVATTA, 2005, p. 3).

Considerando esses conceitos, a integração da formação humana à formação técnica, enquanto uma proposta do Ensino Médio Integrado, requer para a sua implementação ampliar o tempo de formação para articular conhecimento, trabalho e cultura?.

Respeitando-se a autonomia dos sistemas de ensino, a regulamentação dessa modalidade prevê a possibilidade de ampliação da carga horária, que pode ser, dentre outras opções, por meio do acréscimo de mais um ano letivo e/ou pela extensão da carga horária diária, a serem analisadas e regulamentadas pelos respectivos sistemas. Essa ampliação poderá ocorrer, ainda, para o desenvolvimento de atividades relacionadas à ciência, à tecnologia
7 "Entende-se por "tempo integral" as matrículas em turno escolar de duração igual ou superior a sete horas diárias, como referência à $\mathrm{LDB}^{\circ}$ 9.495/96 que, há mais de uma década, preconizava a progressiva ampliação da jornada escolar" (MOLL, 2009, p. 11). 
e à cultura, visando à complementação e/ou ao aprimoramento da formação integral do estudante. (KRAWCZYK, 2009, p. 17).

O que caracteriza a educação integral "[...] é o reconhecimento da necessidade de ampliar e qualificar o tempo escolar, superando o caráter parcial e limitado que as poucas horas diárias proporcionam em estreita associação com o reconhecimento das múltiplas dimensões que caracterizam os seres humanos" (MOLL, 2009, p. 13). Para Moll (2010, p. 72), "[...] parte da crise da jornada completa dos nossos vizinhos latino-americanos acontece porque ela é igual no país inteiro, com a mesma 'grade' curricular e com um tempo estendido no qual acontece "mais do mesmo".

A variável tempo institui-se nessa relação como condição de qualidade para a consolidação do direito à educação. Mas, para além desse aspecto, o tempo compõe o cenário para a restituição de humanidade ao ato de educar, na medida em que mais tempo, e mais tempo ressignificado, pode ensejar diálogos em que cada um diga de si, de sua vida e história, compondo os mosaicos próprios da diversidade, historicamente silenciados na vida escolar. E, nesse sentido, a educação referenciada nos seus sujeitos poderá recuperar o ser humano como referência, apontando para transformações societárias que passam inevitavelmente para a escola. (LECLERC; MOLL, 2013, p. 293).

A ampliação da jornada escolar não se resume, portanto, em oferecer mais horas na escola. A educação integral implica fazer alterações significativas na rotina escolar, ou seja, oferecer novas aprendizagens e uma ressignificação das práticas escolares, buscando, desse modo, a integralidade do desenvolvimento humano.

A demanda por mais tempo diário de escola representa outro lado da moeda da demanda pela qualidade dos processos pedagógicos e pela democratização dos conteúdos científicos, tecnológicos, artísticos e culturais, dos usos de tecnologias e mídias e da participação na produção e disseminação do conhecimento. A potência do conceito de educação integral também representa insumo para a qualificação do tempo diário, em termos da abordagem da base comum nacional nas diferentes áreas de conhecimento, saberes contemporâneos, metodologias, mobilização de atores sociais, profissionais, articulação entre escola, família, comunidade e espaços educativos. (LECLERC; MOLL, 2012, p. 23). 
Contraditoriamente, "[...] a escola fundamental brasileira, especialmente aquela voltada para as classes populares, sempre foi uma escola minimalista, isto é, de poucas horas diárias, pouco espaço e poucos profissionais". Para Cavaliere (2009, p. 51), "[...] incrementar esses três aspectos articulados a um projeto com outras instituições e processos sociais, pode fortalecer a escola como instituição de "socialização e de difusão cultural".

A pauta da educação integral está diretamente relacionada ao enfrentamento de uma lógica perversa e seletiva que atravessa os sistemas de ensino, estruturados em condições desiguais e participando de modo desigual na distribuição de saberes e de oportunidades. Essa pauta é constitutiva da promoção intergeracional, na medida em que os estudantes cujos pais e mães tiveram que buscar o sustento de suas famílias e foram excluídos e esquecidos da vida escolar precisam ter assegurado seu direito de aprender; ela pode auxiliar decisivamente na consolidação dos avanços de escolaridade nas famílias de novos pais e mães, mais jovens, procedentes das condições atuais do ensino médio. (LECLERC; MOLL, 2012, p. 23).

Discutindo as modalidades do Ensino Médio, Krawczyk (2014, p. 30) questiona: “[...] o que seria mais adequado para a realidade brasileira: a universalização da jornada completa no ensino médio ou a oferta de formatos escolares diferentes? Que consequências sociais e educacionais poderiam trazer uma ou outra opção?”. Acreditamos que o direito à educação integrada à formação profissional e a necessidade de ampliação do tempo para a integrar e diversificar o currículo traz à reflexão as contradições inerentes à vida da juventude pobre. Há necessidades que devem ser consideradas no contexto de vida dos jovens, advindas das condições precárias de sobrevivência.

O trabalho juvenil faz parte das formas de socialização da juventude pobre, visto que, em sua maioria, se vê obrigada a prover o seu sustento ou a ajudar suas famílias, o que exclui a possibilidade de dispor de tempo integral para uma formação técnica integrada e integral ou mesmo ao acesso à escola regular integral. É comum ter que deixar de estudar para trabalhar ou mesmo estudar e trabalhar, e ainda há aqueles que não trabalham nem estudam, o que "beira" a situações de vulnerabilidade e até de calamidade.

Diante desse quadro, há a necessidade de garantir o acesso, qualificar a permanência e superar a situação de abandono dos jovens na última etapa da educação básica, o que envolve a articulação de um amplo espectro de políticas públicas inclusivas e abrangentes que garantam sua estada na escola. Abandono da escola em relação aos jovens e dos jovens em relação à escola. Nesse sentido, Ciavatta (2014) ressalta que: 
Se a formação profissional no ensino médio é uma imposição da realidade da população trabalhadora, admitir legalmente essa necessidade é um problema ético-político. Não obstante, se o que se persegue não é somente atender a essa necessidade, mas mudar as condições em que ela se constitui, é também uma obrigação ética e política garantir que o ensino médio se desenvolva sobre uma base unitária, para todos. Portanto, o sentido de formação integrada ou o ensino médio integrado à educação profissional, sob uma base unitária de formação geral, é uma condição necessária para se fazer a travessia para a educação politécnica e omnilateral realizada pela escola unitária. (CIAVATTA, 2014, p. 198).

Além disso, uma mudança de paradigma e a excelência na educação da juventude implicam investimentos para que possam materializar o direito educativo para todos os jovens, rompendo com o dualismo que historicamente ainda predomina: aos pobres uma formação técnica precária e aligeirada; às classes médias e ricas, uma ampla formação escolar.

\section{A Política de Ensino Médio Integrado à Educação Profissional no Brasil}

O Ensino Médio Integrado à Educação Profissional como política pública educacional nacional foi criado durante o governo Luís Inácio Lula da Silva (2003-2006) por meio do Decreto Presidencial $n^{0} 5.154 / 2004$, que substituiu e revogou o Decreto Presidencial em vigor de $n^{0}$ $2.208 / 97^{8}$.

Em 2004, o MEC apresentou a proposta de um ensino médio integrado à educação profissional técnica de nível médio como uma alternativa de ruptura com a histórica dualidade entre formação propedêutica e profissionalizante, que parecia ter-se aprofundado nos anos anteriores. Essa proposta retomou o princípio da politecnia e pretendia superar a dicotomia com a educação profissional, mediante a integração de seus objetivos e métodos, contemplando, num único currículo, os conteúdos da educação geral e da formação profissional, configurando o trabalho como princípio educativo. (LODI; KRAWCZYK, 2008 apud KRAWCZYK, 2014, p. 27-28).

Nesse contexto, vale salientar a importância das políticas e práticas de educação profissional técnica de nível médio que, segundo Moura e Lima Filho (2017, p. 120),
8 Os Decretos foram exarados em 17 de abril de 1997, pelo governo de Fernando Henrique Cardodo, e em 23 de julho de 2004 e 13 de julho de 2006, pelo governo Lula. O primeiro Decreto teve um efeito perverso de consolidação da fragmentação entre a educação geral e a formação profissional. Pela razão aparente de regulamentar artigos da Lei $\mathrm{n}^{\mathrm{O}}$ 9.394/97, o Decreto $\mathrm{n}^{\mathrm{O}} 2.208 / 97$, revogado pelo de $\mathrm{n}^{0}$ 5.154/2004, contrariou os termos da Lei, e uma síntese emblemática do ideário da educação para o mercado, separando o Ensino Médio da Educação Profissional (FRIGOTTO; CIAVATTA, 2011, p. 626). 
tem se destacado positivamente "em concepções e práticas educacionais" em escolas, em estados e municípios e na rede federal nos quais vem "[...] obtendo ao longo dos anos a aprovação da população quanto à qualidade da formação, fato também verificado no desempenho de seus egressos na inserção no mundo do trabalho e/ou na continuidade de estudos no ensino superior”. E ainda:

[...] tais escolas se destacam em qualidade porque, dentre outras razões, reúnem o que em linhas anteriores denominamos condições de funcionamento necessárias, aliadas à concepção de formação humana integral, com a integração entre ciência, tecnologia, cultura e trabalho como eixos norteadores do currículo. (MOURA; LIMA FILHO, 2017, p. 120).

Como uma proposta em desenvolvimento em muitas escolas públicas brasileiras, o ensino médio integral e integrado à educação profissional nos oferece mais uma chance de experimentarmos a formação humana integral e a possibilidade de trilharmos um caminho de inclusão social para juventude. Com o governo de Luiz Inácio Lula da Silva, tendo como ministro da educação Fernando Haddad (2005-2012), uma série de políticas públicas educativas começou a trazer mudanças em todos os níveis de ensino na perspectiva de um governo democrático e popular. Assim, o Decreto $n^{0}$ 5.154/2004 enquanto política de Ensino médio integrado à educação profissional técnica, determinou:

Art. $2^{\circ} \mathrm{A}$ educação profissional será desenvolvida em articulação com o ensino regular ou em modalidades que contemplem estratégias de educação continuada, podendo ser realizada em escolas do ensino regular, em instituições especializadas ou nos ambientes de trabalho.

Art. $3^{\circ}$ A educação profissional compreende os seguintes níveis: I - básico - destinado à qualificação e reprofissionalização de trabalhadores, independente de escolaridade prévia; II - técnico - destinado a proporcionar habilitação profissional a alunos matriculados e egressos do ensino médio, devendo ser ministrado na forma estabelecida por este decreto; III - tecnológico - correspondente a cursos de nível superior na área tecnológica, destinados a egressos do ensino médio e técnico. (BRASIL, 2004, grifos nossos).

Segundo Moll (2017, p. 67), um marco a ser considerado foi a efetivação do Decreto $\mathrm{n}^{0} 5.154 / 2004$ e a revogação do Decreto $n^{0}$ 2.208/98 que fez com que se retomasse 
a perspectiva de um ensino médio com formação humana geral integrado à educação profissional: Art. $4^{\circ}$ - A educação profissional técnica de nível médio, [...] será desenvolvida de forma articulada com o ensino médio [...].

$1^{\mathrm{o}}$ - A articulação entre a educação profissional técnica de nível médio e o ensino médio dar-se-á de forma: I - integrada, oferecida somente a quem já tenha concluído o ensino fundamental, sendo o curso planejado de modo a conduzir o aluno à habilitação profissional técnica de nível médio, na mesma instituição de ensino, contando com matrícula única para cada aluno; II - concomitante, oferecida somente a quem já tenha concluído o ensino fundamental ou esteja cursando o ensino médio, na qual a complementaridade entre a educação profissional técnica de nível médio e o ensino médio pressupõe a existência de matrículas distintas para cada curso, podendo ocorrer: a) na mesma instituição de ensino, aproveitando-se as oportunidades educacionais disponíveis; b) em instituições de ensino distintas, aproveitando-se as oportunidades educacionais disponíveis; ou c) em instituições de ensino distintas, mediante convênios de intercomplementaridade, visando ao planejamento e ao desenvolvimento de projetos pedagógicos unificados; III - subsequente, oferecida somente a quem já tenha concluído o ensino médio. (BRASIL, 2004, grifos nossos).

Para Frigotto e Ciavatta (2011, p. 626), o Decreto $n^{0}$ 5.154/2004 "[...] introduziu a alternativa de articulação do ensino médio com a educação profissional e técnica como formação integrada [...]”, e foi incorporado pela Lei $\mathrm{n}^{\mathrm{O}}$ 11.741, de 16 de julho de 2008.

A proposta é que a organização do ensino médio supere a dicotomia com a educação profissional, mediante a integração de seus objetivos e métodos, contemplando, num único currículo, os conteúdos da educação geral e da formação profissional, configurando o trabalho como princípio educativo. Retoma-se, assim, o princípio da escola politécnica como eixo organizador do currículo, pois, embora se admita a profissionalização, pressupõem-se a integração dos princípios da ciência, do trabalho e da cultura. (LODI et al., 2008 apud KRAWCZYK, 2009, p. 16).

Segundo Krawczyk (2009, p. 16), a proposta é um curso único, integrado e interdependente com os compo- 
nentes curriculares de formação geral ou de base tecnológica de habilitação profissional oferecidos simultaneamente.

A institucionalização dessa nova modalidade educacional implica romper com a dualidade estrutural que historicamente separou o ensino propedêutico da formação profissionalizante no Brasil. Almeja-se com isso, a partir de uma profunda revisão de paradigmas e conceitos que envolvem a questão, eliminar a indesejável oposição entre conhecimento geral e conhecimento específico. (KRAWCZYK, 2009, p. 17).

O Decreto $\mathrm{n}^{\mathrm{O}}$ 5.154/2004 abriu a possibilidade de reduzir a histórica dualidade do Ensino Médio como uma tentativa de ruptura com o sistema dual entre a formação propedêutica e profissionalizante, propondo a integração dos conteúdos da educação geral e da formação profissional. Sobre a ideia de integração, Frigotto e Ciavatta (2011, p. 626-627) advertem:

Guardadas as diferenças históricas, sua origem remota esta na educação socialista, politécnica ou tecnológica (Marx, 1980), que pretendia ser omnilateral no sentido de formar o ser humano na sua integralidade física, mental, cultural, política e científico-tecnológica. A origem recente da ideia de integração entre a formação geral e a educação profissional está nas lutas pela democracia e em defesa da escola pública nos anos de 1980, que buscavam assegurar uma formação básica que superasse a dualidade entre cultura geral e cultura técnica, assumindo o conceito de politecnia.

Em 2007, outro avanço foi o Programa Brasil Profissionalizado, Decreto $\mathrm{n}^{0}$ 6.302, de 12 de dezembro de 2007, destinado à reconstrução das condições de infraestrutura nos estados para oferta de Ensino Médio articulado à educação profissional, e foi publicada a "Base da Educação Profissional Técnica de Nível Médio Integrada ao Ensino Médio" (BRASIL, 2007).

A publicação da Lei $n^{0}$ 11.741, de julho de 2008, alterou a LDB no 9394/96, ao dispor sobre a Educação Profissional Técnica (EPT) de Nível Médio, e passou a ter a seguinte redação: “Art. 36-B. A Educação Profissional técnica de nível médio será desenvolvida nas seguintes formas: I articulada com o ensino médio; II - subseqüente [sic], em cursos destinados a quem já tenha concluído o ensino médio (BRASIL, 2008)". Essa lei tratava “da Educação Profissional" e passou a tratar "da Educação Profissional e Tecnológica” (art. 39) ${ }^{9}$. Outra alteração refere-se à inserção da Educação Profissional no Ensino Médio enquanto
9 “Art. $39-\S 2^{\circ}$ A educação profissional e tecnológica abrangerá os seguintes cursos: I - de formação inicial e continuada ou qualificação profissional; II - de educação profissional técnica de nível médio; III - de educação profissional tecnológica de graduação e pós-graduação" (BRASIL, 2008). 
etapa final da Educação Básica: "Art. 36-A [...] o Ensino Médio, atendida a formação geral do educando, poderá prepará-lo para o exercício de profissões técnicas”. E ainda: "A preparação geral para o trabalho e, facultativamente, a habilitação profissional poderão ser desenvolvidas nos próprios estabelecimentos de ensino médio ou em cooperação com instituições especializadas em educação profissional” (BRASIL, 2008).

No ano seguinte, a Emenda Constitucional n ${ }^{0} 59$, de 11 de novembro de 2009, estabeleceu sua obrigatoriedade para a faixa etária dos 15 aos 17 anos, promovendo o alargamento dos anos de obrigatoriedade da educação básica e um novo direito educativo: "Art. 208. O dever do Estado com a educação será efetivado mediante a garantia de: I - educação básica obrigatória e gratuita dos 4 (quatro) aos 17 (dezessete) anos de idade, assegurada inclusive sua oferta gratuita para todos os que a ela não tiveram acesso na idade própria”. Para Moura e Lima Filho (2017, p. 121), deve-se fazer valer esse direito constitucional: " $E$, na verdade, um bom desafio social, um passo importante e necessário no processo de travessia de uma sociedade desigual e excludente para uma igualitária em que todos estejam incluídos como cidadãos de pleno direito".

Em 2012, a Resolução CNE/CEB no 2/2012 aprovou novas Diretrizes Curriculares Nacionais para o Ensino Médio com fundamento no Parecer CNE/CEB no 5/2011. No mesmo ano, a Resolução $n^{\circ}$ 6, de 20 de setembro, definiu as Diretrizes Curriculares Nacionais para a Educação Profissional Técnica de Nível Médio destacando em seu artigo 30: "A Educação Profissional Técnica de Nível Médio é desenvolvida nas formas articulada e subsequente ao Ensino Médio, podendo a primeira ser integrada ou concomitante a essa etapa da Educação Básica”. Assim, a educação técnica pôde ser desenvolvida articulada (integrada ou concomitante) ao Ensino Médio, e Subsequente, em cursos destinados exclusivamente a quem já tenha concluído o Ensino Médio (art. $7^{0}$ ).

Art. $7^{\circ}$ A Educação Profissional Técnica de Nível Médio é desenvolvida nas formas articulada e subsequente ao Ensino Médio: I - a articulada, por sua vez, é desenvolvida nas seguintes formas: a) integrada, ofertada somente a quem já tenha concluído o Ensino Fundamental, com matrícula única na mesma instituição, de modo a conduzir o estudante à habilitação profissional técnica de nível médio ao mesmo tempo em que conclui a última etapa da Educação Básica; b) concomitante, ofertada a quem ingressa no Ensino Médio ou já o esteja cursando, efetuando-se matrículas distintas para cada curso, aproveitando oportunidades educacionais disponíveis, seja em unidades de ensino da mesma 
instituição ou em distintas instituições de ensino; c) concomitante na forma, uma vez que é desenvolvida simultaneamente em distintas instituições educacionais, mas integrada no conteúdo, mediante a ação de convênio ou acordo de intercomplementaridade, para a execução de projeto pedagógico unificado; II - a subsequente, desenvolvida em cursos destinados exclusivamente a quem já tenha concluído o Ensino Médio. (BRASIL, 2012).

Em 2013, destacamos o Pacto Nacional pelo Fortalecimento do Ensino Médio, Portaria ${ }^{0}$ 1.140, de 22 de novembro de 2013 (BRASIL, 2013b), firmado com os estados que previa, dentre suas ações, a recuperação da infraestrutura das escolas, o acesso aos meios tecnológicos, a línguas estrangeiras e bolsas para formação dos professores. Reafirmado no Plano Nacional de Educação (PNE), Lei $n^{0}$ 13.005, de 25 de junho de 2014, que o coloca como uma de suas estratégias:

O Pacto Nacional pelo Fortalecimento do Ensino Médio, instituído pela Portaria $\mathrm{n}^{0} 1.140$, de 22 de novembro de 2013, representa a articulação e a coordenação de ações e estratégias entre a União e os governos estaduais e distrital na formulação e implantação de políticas para elevar o padrão de qualidade do Ensino Médio brasileiro, em suas diferentes modalidades, orientado pela perspectiva de inclusão de todos que a ele têm direito. (BRASIL, 2014).

De acordo com a política de ensino médio, expressa nas Diretrizes Curriculares Nacionais para a Educação Básica (2013a), busca-se relacionar educação e trabalho, o que em legislações anteriores havia sido separado pelo sistema dual:

O Ensino Médio, etapa final do processo formativo da Educação Básica, é orientado por princípios e finalidades que prevêem [sic]: I - a consolidação e o aprofundamento dos conhecimentos adquiridos no Ensino Fundamental, possibilitando o prosseguimento de estudos; II - a preparação básica para a cidadania e o trabalho, tomado este como princípio educativo, para continuar aprendendo, de modo a ser capaz de enfrentar novas condições de ocupação e aperfeiçoamento posteriores; III - o desenvolvimento do educando como pessoa humana, incluindo a formação ética e estética, o desenvolvimento da autonomia intelectual e do pensamento crítico; IV - a compreensão dos fundamentos científicos e 
tecnológicos presentes na sociedade contemporânea, relacionando a teoria com a prática. (BRASIL, 2013a, p. 39, grifo nosso).

Moll (2017) destaca o Plano Nacional de Educação (PNE) como uma das ações importantes em um contexto de afirmação de direitos e de construção de relações democráticas, uma vez que suas metas e estratégias contribuíram para a consolidação do Ensino Médio como etapa conclusiva da educação básica, como no exposto na Meta 3:

Universalizar, até 2016, o atendimento escolar para toda a população de 15 (quinze) a 17 (dezessete) anos e elevar, até o final do período de vigência deste PNE, a taxa líquida de matrículas no ensino médio para $85 \%$ (oitenta e cinco por cento). (BRASIL, 2014, p. 53).

Essa narrativa histórica, relembrando as políticas educativas do Ensino Médio brasileiro, nos remete à reflexão sobre os dilemas que hoje permeiam o projeto de educação após o impeachment de Dilma Rousseff e a política proposta, a partir de 2016, pelo governo de Michel Temer. Considerando a trajetória das políticas destinadas ao Ensino Médio brasileiro - com seus avanços, contradições e retrocessos - estamos diante da necessidade de implementação das inúmeras diretrizes do Plano Nacional de Educação (2014-2024) e da universalização do Ensino Médio brasileiro, e, contraditoriamente, diante de uma Reforma (Lei $n^{0} 13.145 / 2017$ ) que contraria essas expectativas.

\section{Considerações finais}

As reflexões sobre as políticas públicas em educação destinadas ao Ensino Médio são fundamentais para se repensar as possibilidades abertas para a juventude no Brasil, superando a mera reprodução social a partir do berço e do sobrenome.

A política de Ensino Médio Integrado à Educação Profissional aponta um caminho de garantia da educação da juventude ao buscar, conceitualmente e na prática educativa, a superação das formações diferenciadas para ricos e pobres. Ao propor a integração dos conhecimentos técnicos, científicos e culturais, consequentemente caminha para o enfrentamento do dualismo que marcou historicamente a política de ensino secundário no Brasil. Então, para que essa mudança ocorra, são necessárias transformações tanto nas subjetividades que constituem o universo social e escolar, quanto nas políticas educativas e nas práticas escolares. Nessa perspectiva, seria possível a transformação da escola para constituir-se como espaço de cultura e de formação humana integral, focado na qualidade, socialmente referenciada nas necessidades da formação da juventude brasileira, em um contexto de desigualdades sociais e educacionais. 
A proposição de políticas públicas em educação democráticas, efetivas, propositivas, vivenciadas e recriadas, com autonomia no trabalho pedagógico escolar, deve, no Ensino Médio, não somente estar centrada nos valores éticos, na atitude científica, voltada à análise e resolução dos problemas do país, como também viabilizar a escola pública como instituição propositora de novos rumos para a humanidade, incluindo todos como cidadãos de direito. Residem, nesta dimensão, as possibilidades abertas pelo Ensino Médio Integrado à Educação Profissional no Brasil.

\section{Referências}

ARROYO, Miguel González. O direito a tempos-espaços de um justo e digno viver. In: MOLL, Jaqueline (Org.). Caminhos da educação integral no Brasil: direito a outros tempos e espaços educativos. Porto Alegre: Penso, 2012. p. 33-45.

BRASIL. Constituição (1934). Constituição da República dos Estados Unidos do Brasil. Disponível em: http://www.planalto.gov.br/ccivil_03/Constituicao/ Constitui\%C3\%A7ao34.htm. Acesso em 01 abr. 2019.

BRASIL. Constituição (1937). Constituição dos Estados Unidos do Brasil. Disponível em: http://www.planalto. gov.br/ccivil_03/Constituicao/Constitui\%C3\%A7ao37. htm. Acesso em 1 abr. 2019.

BRASIL. Constituição Federal (1988). Atualizada até a Emenda Constitucional $\mathrm{n}^{\mathrm{O}} 95$ de 15 de dezembro de 2016. Disponível em: http://www2.camara.leg.br/ atividade-legislativa/legislacao/Constituições Brasileiras/ constituicao1988.html. Acesso em: 1 abr. 2019.

BRASIL. Decreto no 2.208, de 17 de abril de 1997. Regulamenta o $\S 2^{\circ}$ do art. 36 e os arts. 39 a 42 da Lei $\mathrm{n}^{\circ}$ 9.394, de 20 de dezembro de 1996, que estabelece as diretrizes e bases da educação nacional. Disponível em: http://www.planalto.gov.br/ccivil_o3/decreto/ D2208.htm. Acesso em:13 abr. 2019.

BRASIL. Decreto no 5.154 , de 23 de julho de 2004. Regulamenta o $\S 2^{\circ}$ do art. 36 e os arts. 39 a 41 da Lei $\mathrm{n}^{\circ}$ 9.394, de 20 de dezembro de 1996, que estabelece as diretrizes e bases da educação nacional, e dá outras providências. Disponível em: http://www.planalto.gov. br/ccivil_03/_Ato2004-2006/2004/Decreto/D5154. htm. Acesso em:13 abr. 2019.

BRASIL. Decreto no 6.302, de 12 de dezembro de 2007. Institui o Programa Brasil Profissionalizado. Disponível em: http://www.planalto.gov.br/ ccivil_03/_Ato2007-2010/2007/Decreto/D6302. htm. Acesso em: 31 ago. 2019. 
BRASIL. Lei no 11.741 de 16 de julho de 2008. Altera dispositivos da Lei $n^{0}$ 9.394, de 20 de dezembro de 1996, que estabelece as diretrizes e bases da educação nacional, para redimensionar, institucionalizar e integrar as ações da educação profissional técnica de nível médio, da educação de jovens e adultos e da educação profissional e tecnológica. Disponível em: http://www.planalto.gov. br/ccivil_03/_ato20072010/2008/lei/l11741.htm. Acesso em: 31 ago. 2019.

BRASIL. Emenda Constitucional $n^{0}$ 59, de 11 de novembro de 2009. Acrescenta $\S 3^{\circ}$ ao art. 76 do Ato das Disposições Constitucionais Transitórias para reduzir, anualmente, a partir do exercício de 2009, o percentual da Desvinculação das Receitas da União incidente sobre os recursos destinados à manutenção e desenvolvimento do ensino de que trata o art. 212 da Constituição Federal, dá nova redação aos incisos I e VII do art. 208, de forma a prever a obrigatoriedade do ensino de quatro a dezessete anos e ampliar a abrangência dos programas suplementares para todas as etapas da educação básica, e dá nova redação ao $\S 4^{\circ}$ do art. 211 e ao $\S 3^{\circ}$ do art. 212 e ao caput do art. 214, com a inserção neste dispositivo de inciso VI. Disponível em: planalto.gov.br/ccivil_03/ constituicao/Emendas/Emc/emc59.htm. Acesso em: 10 mar. 2014.

BRASIL. Ministério da Educação. Conselho Nacional de Educação. Câmara de Educação Básica. Resolução no 2, 30 de janeiro de 2012a. Define Diretrizes Curriculares Nacionais para o Ensino Médio. Disponível em: http://educacaointegral.mec.gov.br/images/pdf/res_ ceb_2_30012012.pdf. Acesso em: 10 mar. 2014.

BRASIL. Resolução CNE/CEB no 6, de 20 de setembro de 2012b. Define Diretrizes Curriculares Nacionais para a EducaçãoProfissionalTécnicadeNívelMédio.Disponívelem: http://portal.mec.gov.br/index.php?option $=$ com_ d oc man \&view =d ownload \&alias $=11663^{-}$ rceboo6-12-pdf\&category_slug=setembro-2012pdf\&Itemid=30192. Acesso em: 3 maio 2017.

BRASIL. Ministério da Educação. Secretaria de Educação Básica. Diretoria de Currículos e Educação Integral. Diretrizes Curriculares Nacionais Gerais da Educação Básica. Brasília: MEC, SEB, DICEI, $2013 a$.

\footnotetext{
BRASIL. Portaria no 1.140, de 22 de novembro de 2013b. Institui o Pacto pelo Fortalecimento do Ensino Médio. Disponível em: http:// portal.mec.gov.br/index.php?option $=\mathrm{com}_{-}$ docman\&view=download\&alias $=15069$-pacto-dou-12\&category_slug=janeiro-2014-pdf\&Itemid=30192. Acesso em: 31 ago. 2019.
} 
BRASIL. Lei no 13.005 de 25 de junho de 2014. Aprova o Plano Nacional de Educação e dá outras providências. Disponível em: http://www.planalto.gov.br/ccivil_03/_ Ato2011-2014/2014/Lei/L13005.htm. Acesso em: 8 jan.2019

BRASIL. Lei no 13.145, de 16 de fevereiro de 2017. Altera a Lei $\mathrm{n}^{\circ}$ 9.394, de 20 de dezembro de1996, que estabelece as diretrizes e bases da educação nacional. Disponível em: www.planalto.gov.br/ccivil_03/_ Ato2015-2018/2017/Lei/L13415.htm. Acesso em: 8 jan. 2019.

BRASIL. Resolução no 3 , de 21 de novembro de 2018. Atualiza as Diretrizes Curriculares Nacionais para o Ensino Médio. Disponível em: portal.mec.gov.br/ index.php?option $=$ com_docman\&view $=$ download\&ali as $=102481$-rceboo3-18\&category_slug=novembro-2018pdf\&Itemid=30192. Acesso em: 8 jan. 2019.

CAVALIERE, Ana Maria. Escolas de tempo integral versus alunos em tempo integral. Em Aberto, Brasília, v. 22, n. 8o, p. 51-63, abr. 2009.

CIAVATTA, Maria. A formação integrada: a escola e o trabalho como lugares de memória e de identidade. Revista Trabalho Necessário, Rio de Janeiro, ano 3, n. 3, p. 1-20, 2005.

CIAVATTA, Maria. O ensino integrado, a politecnia e a educação omnilateral. Por que lutamos? Trabalho \& Educação, Belo Horizonte, v. 23, n. 1, p. 187-205, jan./ abr. 2014.

CURY, Carlos Roberto Jamil. A Educação Como Desafio na Ordem Jurídica. In: LOPES, Eliane Martha Teixeira; FARIA FILHO, Luciano Mendes de; VEIGA, Cynthia Greive. 500 anos de educação no Brasil. Belo Horizonte: Autêntica, 2000. p. 567-570.

CURY, Carlos Roberto Jamil. Políticas inclusivas e compensatórias na educação básica. Cadernos de Pesquisa, São Paulo, v. 35, n. 124, p. 11-32, jan./abr. 2005.

FREIRE, Paulo. Pedagogia do Oprimido. Rio de Janeiro: Paz e Terra, 1987.

FRIGOTTO, Gaudêncio; CIAVATTA, Maria. Perspectivas sociais e políticas da formação de nível médio: avanços e entraves nas suas modalidades. Educação Sociedade, Campinas, v. 32, n. 116, p. 619-638, jul./set. 2011.

INSTITUTODEESTUDOSE PESQUISASEDUCACIONAIS ANISIO TEIXEIRA(INEP). Censo Escolar da educação Básica 2017. Disponível em: http://portal.inep.gov.br/ censo-escolar. Acesso em: 13 mar. 2018. 
KRAWCZYK, Nora. O ensino médio no Brasil. São Paulo: Ação Educativa, 2009.

KRAWCZYK, Nora. Ensino médio: empresários dão as cartas na escola pública. Educação \& Sociedade, Campinas, v. 35, n. 126, p. 21-41, jan./mar. 2014.

LECLERC, Gesuína de Fátima Elias; MOLL, Jaqueline. Diversidade e tempo integral: a garantia dos direitos sociais. Revista Retratos da Escola, Brasília, v. 7, n. 13, p. 291-304, jul./dez. 2013.

LECLERC, Gesuína de Fátima Elias; MOLL, Jaqueline. Educação integral em jornada diária ampliada: universalidade e obrigatoriedade?. Em Aberto, Brasília, v. 25, n. 88, p. 17-49, 2012.

MOLL, Jaqueline. Um paradigma contemporâneo para a educação integral. Revista Pátio, Porto Alegre, n. 51, p. 12-15, ago./out. 2009.

MOLL, Jaqueline. A política de educação integral no Brasil: mais educação. In: CENPEC. Colóquio Educação integral. São Paulo: CENPEC, 2010. p. 70-79

MOLL. Jaqueline. Reformar para retardar: a lógica da mudança no EM. Revista Retratos da Escola, Brasília, v. 11, n. 20, p. 61-74, jan./jun. 2017.

MOURA, Dante Henrique; LIMA FILHO, Domingos Leite. A reforma do ensino médio Regressão de direitos sociais. Revista Retratos da Escola, Brasília, v. 11, n. 20, p. 109129, jan./jun. 2017.

NOSELLA, Paolo. Ensino médio unitário ou multiforme? Revista Brasileira de Educação, Rio de Janeiro, v. 20 n. 6o, p. 121-142, jan./mar. 2015.

SOUZA, Jessé. A Ralé Brasileira: quem são e como vivem. Belo Horizonte: Ed. UFMG, 2009.

SOUZA, Francisco das Chagas Silva; COSTA JÚNIOR, José Gerardo Bastos da; SOUZA, Francisca Leidiana. Ensino médio integrado: a produção do conhecimento nos anos 2007 a 2017. IFRN Revista Eletrônica Científica Ensino Interdisciplinar Mossoró, Mossoró, v. 4, n. 12, p. 643-659, nov. 2018. 